\title{
Uma Análise Comparativa entre Diferentes Versões de Variantes Modernas do Processo MIG/MAG para o Passe de Raiz em Soldagem Orbital
}

\author{
Francisco Sartori ${ }^{1}$, Régis Henrique Gonçalves e Silva ${ }^{1}$, Jair Carlos Dutra ${ }^{1}$, Luiz Eduardo dos Santos Paes ${ }^{1}$, \\ Mateus Barancelli Schwedersky ${ }^{1}$, Cleber Marques ${ }^{1}$
}

${ }^{1}$ Universidade Federal de Santa Catarina - UFSC, Instituto de Soldagem e Mecatrônica - LABSOLDA, Florianópolis, SC, Brasil.

Recebido: 16 Nov., 2017

Aceito: 21 Nov., 2017

E-mail: fsartori@hotmail.com.br (FS)
Este é um artigo publicado em acesso aberto (Open Access) sob a licença Creative Commons Attribution Non-Commercial, que permite uso, distribuição e reprodução em qualquer meio, sem restriçōes desde que sem fins comerciais e que 0 trabalho original seja corretamente citado.
Resumo: O presente trabalho visa obter o conhecimento detalhado de diferentes versões do processo MIG/MAG por transferência em curto-circuito com controle de corrente e sua aplicabilidade na soldagem de raiz em chanfro $V$ sem a utilização de anteparo da poça (backing). Embora muitos trabalhos na área de soldagem de tubos descrevam realizar o procedimento inteiramente mecanizado através de sistemas orbitais, informações mais detalhadas sobre como este foi realizado acabam não sendo divulgadas. Além disso, diferentes condições de aplicação impõem conhecimento mais aprofundado, para devida adaptação / parametrização específica. Nesse contexto, a soldagem de raiz com manipulador orbital mecanizado foi realizada em tubos utilizados na indústria do petróleo e gás, verificando as condições de operação de três versões comerciais do processo MIG/MAG em curto-circuito com controle de corrente, sendo duas com controle eletrônico e uma com controle eletromecânico da transferência metálica. As três versões possuem níveis controlados de energia, bom controle de estabilidade na transferência metálica e baixo índice de respingos, diferenciais na aplicação de raiz. Nos ensaios, feitos em tubos da classe API $5 \mathrm{~L}$ grau B, foi possível a realização da soldagem orbital em situações nas quais a junta dos tubos apresentava geometria favorável, sem a presença de desnivelamento (high-low) e em condições estreitas dos valores de tolerância para abertura de raiz (gap). Quanto ao perfil geométrico de fusão no chanfro, os ensaios com as versões eletrônicas apresentaram bons resultados sem defeitos que pudessem comprometer a integridade da junta. No entanto, dentro das faixas abordadas, com a utilização da versão eletromecânica, verificou-se a presença de defeitos de falta de fusão, o que gerou hipóteses quanto a diferentes faixas de parâmetros para esta versão na aplicação de raiz em tubos com chanfro V.

Palavras-chave: GMAW; Soldagem orbital; Mecanização.

\section{A Comparative Analysis of Different Versions of the MIG/MAG Process Modern Variants for the Root Pass in Orbital Welding}

\begin{abstract}
The present work aims to obtain the detailed knowledge of different versions of the MIG/MAG process by short-circuit transfer with current control and its applicability in V-groove root welding without the use of backing. Although many pipe welding researches describe performing the fully machined procedure through orbital systems, more detailed information on how this was accomplished ends up not being disclosed. In addition, different application conditions require in-depth knowledge for proper adaptation/specific parameterization. In this context, root welding with a mechanized orbital manipulator was performed in tubes used in the oil and gas industry, by verifying the operating conditions of three commercial versions of the MIG/MAG process in short circuit with current control, two of which with electronic control and one with electromechanical control of metal transfer. The three versions have controlled levels of energy, good stability control on the metal transfer and low spatter index, differentials in root application. In the tests, which were carried out on API $5 \mathrm{~L}$ grade $B$ pipes, it was possible to perform orbital welding in situations in which the pipe joint presented favorable geometry, without the presence of unevenness (high-low) and narrow conditions of tolerance values for gap opening. As for the geometric profile of fusion on the groove, the tests with the electronic versions presented good results without defects that could compromise the integrity of the joint. However, within the ranges covered, with the use of the electromechanical version, it was verified the presence of lack of fusion defects, which generated hypotheses regarding different parameter ranges for this version in the root application in V-groove tubes.
\end{abstract}

Key-words: GMAW; Orbital welding; Mechanization. 
Uma Análise Comparativa entre Diferentes Versões de Variantes Modernas do Processo MIG/MAG para o Passe de Raiz em Soldagem Orbital

\section{Introdução}

Embora formas diferenciadas de fontes de energias renováveis estejam surgindo com grande expansão, a indústria de petróleo e gás natural faz-se ainda imprescindível no atual cenário econômico-industrial do país. Formas diretas e indiretas de industrialização dependem desse consumo, e em meio a crescente necessidade, é cada vez maior a exigência por métodos mais eficazes no transporte desses produtos. Um meio mais produtivo e seguro é o escoamento através de linhas de dutos, as quais já há alguns anos, países produtores têm realizados grandes investimentos com resultados expressivos.

Em atividades de construção, montagem, reparo e manutenção de dutos, a soldagem é o principal processo de fabricação utilizado, com o objetivo de conceder integridade estrutural das juntas. Ademais, processos de soldagem mais produtivos influenciam diretamente nos custos, cronogramas, análise de riscos e viabilização de projetos.

A carência de profissionais qualificados e as dificuldades para a execução da atividade de soldagem em tubos, principalmente no passe de raiz é evidente. Tipicamente, a soldagem de tubos é realizada com um passe de raiz com processo TIG e preenchimento com soldagem por eletrodo revestido, ambos manuais [1]. Já em alguns casos, dependendo da disponibilidade e a qualificação dos soldadores, a raiz também é executada com eletrodos revestidos, normalmente celulósicos. Entretanto, a tendência mundial no setor dutoviário é a utilização do processo de soldagem MIG/MAG, e principalmente aplicado com sistemas mecanizados [2-4].

Principalmente para a mecanização, na qual há menor margem para não conformidades na montagem dos tubos e na regulagem das variáveis, o principal desafio na soldagem orbital é constituído pela necessidade de sustentar a poça de fusão em posições que desafiam a gravidade e, por isso, há a necessidade de estratégias muito bem concebidas a fim de que a poça metálica se sustente no espaço. Portanto, a energia de soldagem tem de se situar em uma determinada faixa de valores específicos.

Ainda que o processo MIG/MAG seja uma opção favorável na execução do passe de raiz, a versão curto-circuito convencional com comando em tensão é um fator limitante, porque não atua diretamente na corrente que é a variável de influência determinante para a solda. A atuação indireta restringe determinados objetivos, dificultando o controle do passe de raiz no fundo dos chanfros devido à variação da corrente quando a tocha se desloca com movimento de oscilação dentro da junta [5]. O padrão de variação de corrente é extremamente crítico para a soldagem do passe de raiz, em razão de a solda estar em uma situação de equilíbrio entre a falta de penetração e a perfuração, a boa molhabilidade e o escorrimento.

Uma solução nesses casos é o uso de um backing de cobre para sustentar a poça de fusão. Com o uso desse anteparo, é possível aumentar a velocidade de alimentação do arame (Va) no processo MIG/MAG. Tal aumento gera, consequentemente, a elevação da corrente a um patamar que, dificilmente, acarreta defeito de falta de penetração total na raiz. Porém, o uso de backing fabricado com cobre pode gerar contaminação no metal de solda [6], o que levaria a ocasionar fragilização do metal de base e também perda nas propriedades mecânicas [7]. Em países Europeus, essa prática é rejeitada por parte das empreiteiras, devido à contaminação dele decorrente. Outra desvantagem no uso do backing de cobre é a capacidade de condutividade térmica elevada desse material, o que deve ser considerada no procedimento em relação aos cálculos de pré-aquecimento dos tubos [8], pois despende em maior tempo e custos no processo.

Uma alternativa da minimização das problemáticas da versão com curto-circuito convencional MIG/MAG, e muito utilizado em várias aplicações de construção de linhas de tubos no mundo sem o uso de backing, é o uso de versões MIG/MAG em curto-circuito com controle de corrente. Para esse tipo de transferência, modulam as formas de onda de corrente de modo que se obtenha um dimensionamento adequado das gotas transferidas [9] e da energia aportada. A tecnologia de controle da corrente permite um nível de controle da poça de fusão que habilita seu uso para o passe de raiz [10].

Existem no mercado diversas opções de versões do processo, mas podem se resumir entre as que controlam apenas parâmetros elétricos/eletrônicos, e as que controlam também a dinâmica do arame, eletromecanicamente.

$A$ abordagem de chanfro $V$ é importante para o setor da soldagem de tubos, pois muitas empresas não têm acesso ou condições de possuir equipamentos para realização de outros tipos de chanfros mais favoráveis, por exemplo, chanfro U. Por isso, como os tubos vêm chanfrados de fábrica com perfil para montagem em $V$, o procedimento se torna primordial para a mecanização. 
Com o intuito de utilizar essas tecnologias para a aplicação industrial, aliando as vantagens preconizadas pelos fabricantes, é que o trabalho vem sendo desenvolvido, estudando a aplicação em sistemas mecanizados para a execução do passe de raiz em tubos. O objetivo principal foi investigar e conhecer essas versões, avaliando as particularidades de cada uma, verificar as variáveis elétricas e os resultados dos perfis geométricos dos cordões nas diferentes posições de soldagem de raiz em tubos, assim como a verificação / avaliação da existência de faixas operacionais para as diferentes macro-versões.

\section{Materiais e Equipamentos}

Para a realização dos ensaios, foram utilizados tubos de aço de baixo carbono da especificação API 5L Grau B, com diâmetro externo de 16" (406,4 mm) e espessura de parede 1/2" (12,7 mm). Primeiramente, foram usinadas as extremidades do tubo com chanfradeira/biseladora hidráulica e montado o chanfro em "V", ângulo de abertura total $60^{\circ}$, sem nariz. Na montagem das juntas, tomou-se cuidado com o melhor posicionamento entre os tubos, a fim de se evitar desalinhamentos e variações de abertura da raiz, que pudessem de alguma forma interferir na soldagem. As verificações dessas medidas foram feitas com calibre de solda, tendo como valor de referência a abertura da raiz ao longo da junta entre $2,5 \mathrm{~mm}$ e $3,0 \mathrm{~mm}$.

O equipamento utilizado em todos os ensaios para a manipulação da tocha no percurso dos tubos foi o Tartílope V3, que constitui um desenvolvimento tecnológico do LABSOLDA [11]. Esse manipulador robótico se desloca sobre um trilho, como mostrado na Figura 1, de modo que pode ser realizada a regulagem das variáveis de movimentos antes e durante a execução da solda.

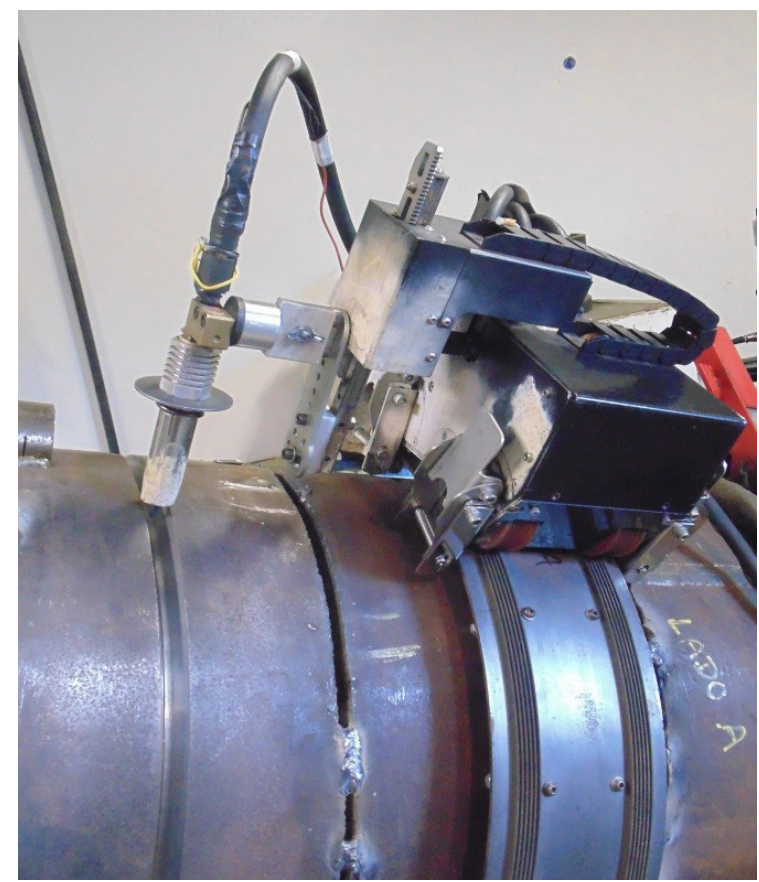

Figura 1. Manipulador robótico Tartílope V3.

Nos ensaios para raiz com as versões eletrônicas do processo MIG/MAG com controle de curto-circuito, a tocha aletada refrigerada a gás, da marca SPA foi empregada. Essa tocha, ao contrário de vários modelos que utilizam o sistema de rosca para o bico de contato, dispõe de um sistema de pinça para fixar o bico de contato. Isso permite a alteração da altura da distância do bico de contato peça (DBCP) apenas com a regulagem do bico de contato, sem alterar a altura do bocal. Para a versão eletromecânica do processo MIG/MAG com controle de curto-circuito, a tocha utilizada foi a do próprio sistema comercial integrado, refrigerada à água e na configuração push-pull.

Como metal de adição usou-se o arame ER70S-6 de 1,2 mm, proteção gasosa com a mistura C 25 (75\% Ar, 25\% CO2) e vazão de $15 \mathrm{~L} / \mathrm{min}$. 
Uma Análise Comparativa entre Diferentes Versões de Variantes Modernas do Processo MIG/MAG para o Passe de Raiz em Soldagem Orbital

Para a aquisição de dados, empregou-se o Sistema de Aquisição Portátil - SAP, do fabricante IMC. O sistema faz a aquisição de sinais de corrente, tensão e velocidade de arame em uma frequência de $5 \mathrm{kHz}$. Os dados aquisitados são dispostos em formas de gráficos e histogramas, permitindo análises detalhadas do procedimento realizado. Além do mencionado, podem ser analisados trechos específicos independentemente dos demais trechos aquisitados, o que permite uma verificação detalhada de algum evento ocorrido.

\section{Metodologia}

Considerando-se que é bastante comum a divisão da seção de um tubo como se fosse um relógio, as soldas foram executadas todas na progressão descendente, sem a utilização de anteparo da poça de fusão (backing). A solda iniciou-se a partir da posição $12 \mathrm{~h}$ até $6 \mathrm{~h}$, percorrendo $180^{\circ}$ do tubo. Para as análises de resultados, foi estipulado que a posição $11 \mathrm{~h}$ do tubo referenciava-se à posição plana (PP), 9h à posição vertical descendente (PV) e $7 \mathrm{~h}$ à posição sobrecabeça (SC). Outra questão que vale ressaltar é que esses ensaios foram todos executados no sentido anti-horário, devido ao melhor arranjo da bancada de ensaios (melhor disposição de cabos, de fontes, sistemas de aquisição de dados, etc.).

A fim de se encontrar variáveis de soldagem aceitáveis para uma solda de qualidade para a raiz, ensaios preliminares foram realizados em tubos com as versões eletrônicas. Primeiramente, com a soldagem manual e a verificação de movimento do soldador, e posteriormente com a adaptação para a soldagem mecanizada.

Em ambas as versões MIG/MAG, foram usados programas sinérgicos. Na versão eletrônica nacional (ME1), o programa sinérgico foi regulado com a velocidade de alimentação de arame (Va) regulada foi de 3,3 $\mathrm{m} / \mathrm{min}$, e os parâmetros "a" em 30; "Cta" em 1,0; e "Ckr" em 0,0 - parâmetros que atuam no refinamento do programa sinérgico, sendo que "a" atua nos patamares de corrente após a formação da gota, Cta atua no tempo do pulso de corrente após a reabertura do arco e Ckr atua no tempo de detecção de reabertura do arco. Já na versão eletrônica estrangeira (ME2), o sinérgico utilizado foi regulado com Va em 3,3 m/min. O parâmetro "Trim", que atua no tempo e inclinação (taxa de descida) da onda de corrente após o pulso de corrente de formação da gota foi regulado em 1,25. A variação desse valor, como consequência, altera a frequência de curto-circuito.

A ideia inicial seria manter a mesma Va em todas as versões, inclusive na eletromecânica (MEM). No entanto, esta versão age e reage de uma forma diferente comparada com as eletrônicas, pois age no sentido de manter um valor constante de corrente média $(\mathrm{Im})$ ao longo da soldagem. Quando há uma alteração na DBCP em virtude da ovalização normal dos tubos, o sistema atua na variação da Va, em transitórios. Algumas dessas características foram verificadas com a realização de simples depósitos sobre chapa, com diferentes ajustes de DBCP para uma mesma regulagem na fonte. Outro ponto observado nos ensaios preliminares foi a constatação de que a programação da Va em 3,3 m/min implicou um valor de tensão extremante baixo, resultando em diferente faixa de energia em relação ao ME1 e ME2. Como consequência, o arco tendenciava ancorar apenas em um dos lados do chanfro, o que é resultado da baixa energia. Com isso, o arco não ancorava em toda a região do chanfro e a poça não molhava nas suas paredes. Para o MEM, o programa sinérgico utilizado foi regulado em 5,9 $\mathrm{m} / \mathrm{min}$, em vez de 3,3 m/min, como solução para fazer uma raiz manual de boa qualidade. O parâmetro "CA" foi mantido em -10 - parâmetro este que atua nos tempos de corrente de cada evento, consequentemente agindo no aumento ou na diminuição da frequência de destacamento.

Na realização da soldagem mecanizada foram mantidas as mesmas variáveis de movimento em todos os ensaios. A Tabela 1 mostra os valores utilizados.

Tabela 1. Variáveis de movimento na soldagem com chanfro V.

Velocidade de Soldagem (Vs): 16 a $19 \mathrm{~cm} / \mathrm{min}$
Amplitude de Tecimento (At): $3 \mathrm{~mm}$
Frequência de Tecimento $(\mathrm{f}): 1,5 \mathrm{~Hz}$
Tempo de Parada em Cada Extremidade (tp): $100 \mathrm{~ms}$
Ângulo de inclinação da tocha: $5^{\circ}$ Puxando
DBCP: $17 \mathrm{~mm}$
Perfil de Tecimento: Trapezoidal


Depois de ter variáveis de soldagem satisfatórias com o sistema mecanizado, definidos por testes preliminares, uma junta com cada versão de processo foi soldada para validação. Depois de soldada, realizou-se uma inspeção visual para análise dos cordões e, por fim, corte de macrografias nas três posições estipuladas, posição plana (PP); posição vertical descendente (PV); e posição sobrecabeça (SC), para análise interna do cordão e de suas condições geométricas de fusão no chanfro.

\section{Análise do Procedimento}

A fim de atingir os objetivos da pesquisa, algumas análises quantitativas e qualitativas foram realizadas: a verificação de cada versão com relação ao comportamento do arco dentro do chanfro, o comportamento da poça ao longo das posições de soldagem, o ponto de contato do arame em relação à poça e a estabilidade do processo.

Um importante ponto a ser considerado é a relação do ancoramento do arco com o chanfro. Na versão MEM, quando estabelecido na fonte de soldagem uma velocidade de arame (Va) de $3,3 \mathrm{~m} / \mathrm{min}$, o valor da tensão registrada no painel indicador da fonte foi de apenas $12 \mathrm{~V}$. Nessa situação, o arco ancorava apenas em um dos lados do chanfro. Foi observado que o arco tende a seguir em uma região mais favorável à passagem da corrente, fazendo com que a poça de fusão não tenha atuação precisa em ambos os lados do chanfro. Ficou evidenciado que, para a situação de chanfro proposta, essa regulagem de variáveis inviabilizava boa solda.

Outro ponto importante analisado no programa sinérgico da versão MEM foi a variação da Va devido à variação da DBCP. O sistema adaptativo funciona mantendo sua transferência em curto-circuito ou a Im em valores constantes, independentemente do aumento ou diminuição da DBCP ao longo do percurso da solda no tubo. O que varia é a Va, na qual o sistema adaptativo atua a fim de que não sejam alteradas as variáveis citadas acima e de que seja mantida a relação da taxa de fusão do arame. Os valores de Va impostos como valor de entrada na fonte não obedecem ao valor de referência, o que não torna factível ao operador regular o equipamento com base nessa informação. Em sua tese, Pépe [12] mostra esta variação em ensaio com a versão MEM, na qual regula uma Va de 7,8 m/min, mostrada na Figura 2. É exposto no gráfico um comportamento praticamente linear dessa variação, no qual foi observado que, em função da variação da $\mathrm{DBCP}$, tem-se a variação de Va para compensar a ação do efeito Joule na taxa de fusão do arame, e assim, não alterar a Im ou a frequência de destacamento.

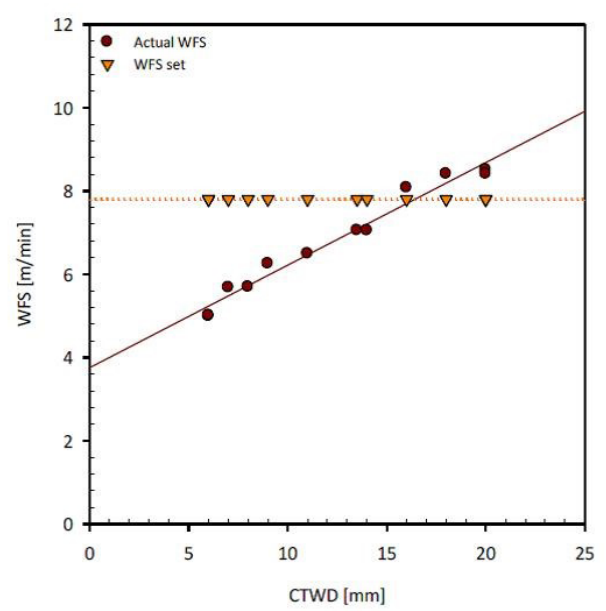

Figura 2. Comportamento da variação de Va pela alteração da DBCP - versão MEM [12].

Na Figura 3a, em ensaios realizados sobre chapas, comprovou-se a análise realizada por Pépe. Porém, nesse caso, utilizou-se a mesma Va usada nos ensaios deste trabalho, nos quais foi regulado 5,9 $\mathrm{m} / \mathrm{min}$ de Va para a versão MEM.

Com relação às versões ME1 e ME2, o comportamento do sinérgico é similar entre si, de maneira que a variação da DBCP mantém a Va constante. Nesses casos, a variável que altera, para compensar o efeito Joule na taxa de fusão do arame, é a Im. A Figura 3b mostra essa variação em ensaio com a versão ME1 e a Va regulada em 3,3 m/min. 
Uma Análise Comparativa entre Diferentes Versões de Variantes Modernas do Processo MIG/MAG para o Passe de Raiz em Soldagem Orbital

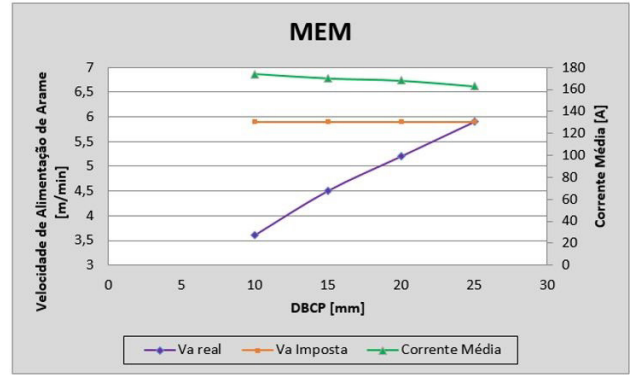

a

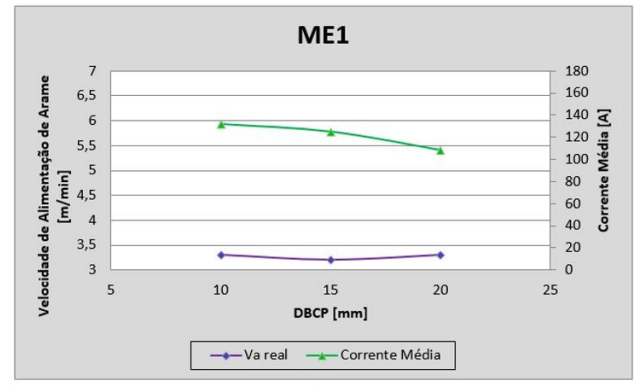

b

Figura 3. (a) Gráfico da relação da variação de Va pela alteração da DBCP - versão MEM; (b) Gráfico da relação da variação de Im pela alteração da DBCP - versão ME1.

Nessa situação, percebeu-se a não linearidade da variação, havendo uma queda mais contundente da Im na variação da DBCP entre $15 \mathrm{~mm}$ e $20 \mathrm{~mm}$.

A soldagem orbital em tubos apresenta diferentes posições ao longo de seu perímetro; e, com isso, foi necessário que a variação da velocidade de soldagem (Vs) fosse alterada devido ao escorrimento da poça de fusão. Para todas as versões, essa variação aconteceu principalmente na posição vertical descendente. O operador do equipamento de soldagem mecanizada, mediante sua percepção visual, ajustou a Vs do equipamento no sentido de manter as gotas destacando no centro da poça. Essa é a condição mais favorável de funcionamento das versões em curto-circuito com controle de corrente, com o objetivo de concentrar energia na poça para obter a penetração requerida.

No decorrer da soldagem, as três versões apresentaram bons resultados quanto à estabilidade da transferência, os quais foram verificados em análises de oscilogramas. A Figura 4 mostra parte dessa estabilidade que se repetiu ao longo de toda a soldagem. Em uma análise qualitativa durante os ensaios, a quantidade de respingos foi mínima - uma das características do bom funcionamento dessas versões.

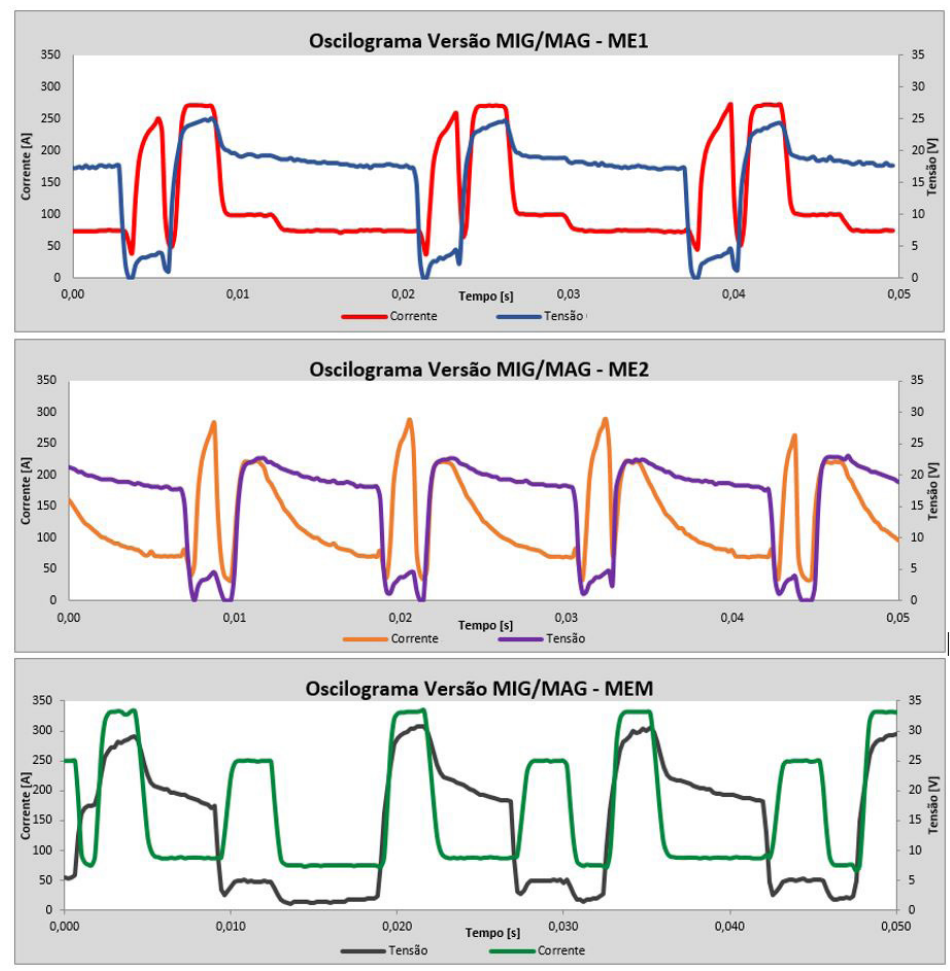

Figura 4. Oscilogramas das versões MIG/MAG - ME1, ME2, MEM - respectivamente. 


\section{Análise das Soldas}

Primeiramente, uma avaliação visual dos cordões de solda foi feita com o intuito de verificar a existência de descontinuidades que os comprometessem. Descontinuidades como penetração incompleta, concavidade excessiva da raiz, reforço excessivo da raiz, perfuração, poros superficiais, mordeduras e falta de fusão não foram observadas nos cordões. A Figura 5 mostra uma visão geral da face e da raiz obtida em cada versão de processo.

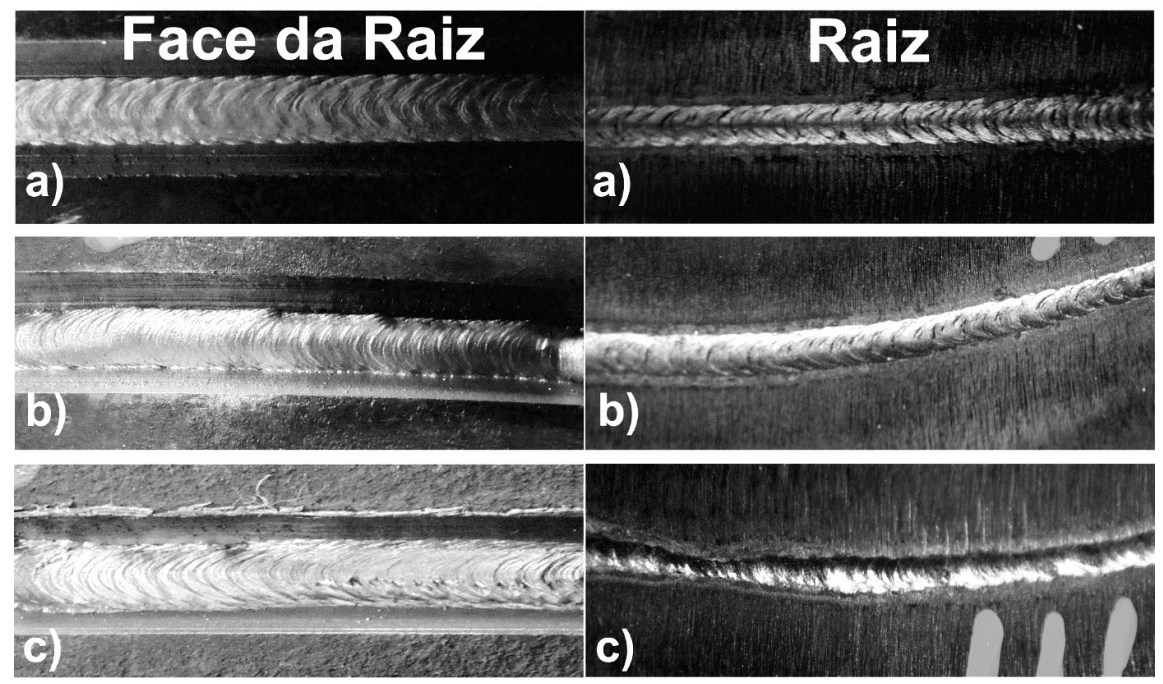

Figura 5. Cordão de raiz em ensaio de validação do chanfro V - (a) ME1; (b) ME2; (c) MEM.

Para uma análise mais detalhada do perfil geométrico do metal fundido e uma melhor condição de visualização das descontinuidades, macrografias mostradas na Figura 6 foram preparadas. Para cada posição de soldagem, plana (PP), vertical descendente (PV) e sobrecabeça (SC), foram cortadas amostras em uma mesma referência pontual nos tubos.
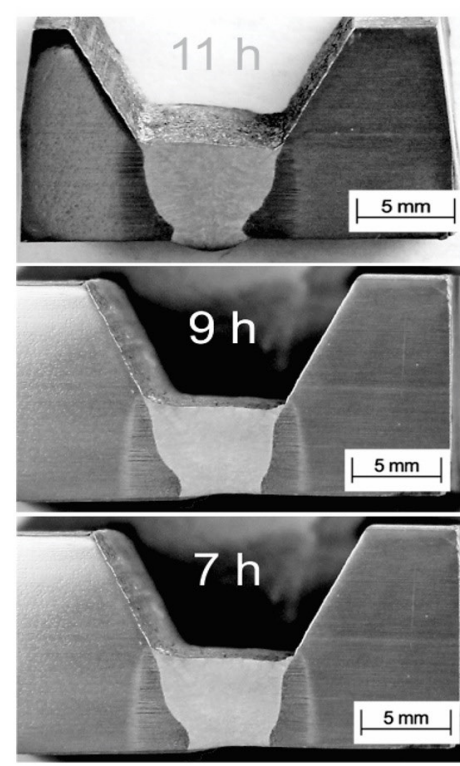

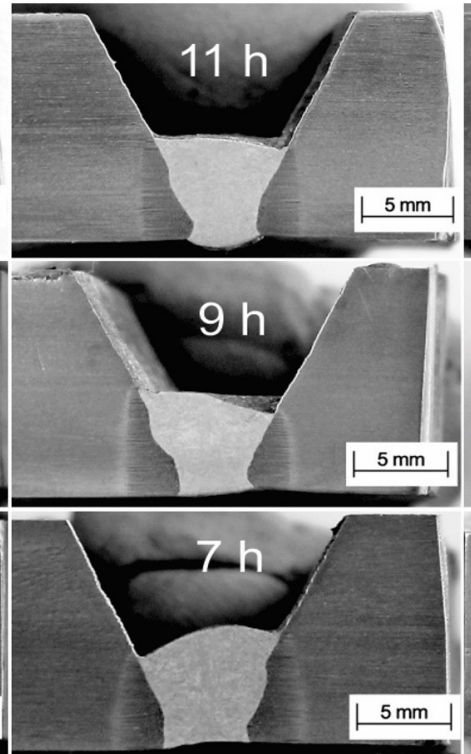

$\mathrm{b}$

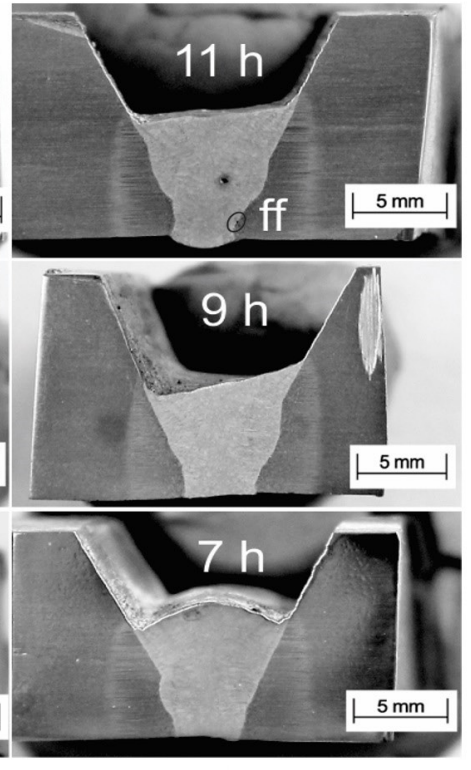

$\mathrm{C}$

Figura 6. Macrografias (a) ME1 - PP, PV, SC respectivamente (b) ME2 - PP, PV, SC respectivamente (c) MEM - PP, $\mathrm{PV}, \mathrm{SC}$ respectivamente ( $\mathrm{PP}=11 \mathrm{~h}, \mathrm{PV}=9 \mathrm{~h}, \mathrm{SC}=7 \mathrm{~h})$. 
Uma Análise Comparativa entre Diferentes Versões de Variantes Modernas do Processo MIG/MAG para o Passe de Raiz em Soldagem Orbital

Nos resultados, apenas a versão MEM mostrou não atender plenamente às condições exigíveis. Na amostra da posição plana, mostrada na Figura $6 c$, além do poro identificado no centro do metal fundido, o que pode ser uma condição esporádica, a falta de fusão (ff) é perceptível em um dos flancos do chanfro, comprometendo a integridade da raiz por ser um concentrador de tensões.

Embora as versões ME2 e MEM na posição sobrecabeça tenham apresentado maior convexidade na superfície da raiz, o que não é considerado defeito perante as normas, os demais resultados mostraram-se de boa qualidade, principalmente no que concerne às versões ME1 e ME2, nas quais, em todas as posições do tubo, obteve-se boa fusão nos flancos do chanfro.

Outro ponto analisado foi em relação ao modo como a alteração do comportamento da poça de fusão, ao longo das posições do tubo, influenciou em um perfil solidificado diferente à cada posição, porém, similar entre as versões. Na posição plana, é nítida a presença de reforço de raiz. Para a posição vertical descendente e sobrecabeça, a raiz ficou com aspecto semelhante; entretanto, em alguns casos, uma pequena concavidade interna ocorreu em relação ao tubo.

No que concerne à espessura de metal depositado, nas versões eletrônicas, foi constatada a similaridade de valores. O MEM, em decorrência do aumento da Va regulada na fonte em 5,9 m/min, resultando em uma $V$ a real de $4,7 \mathrm{~m} / \mathrm{min}$, obteve uma maior espessura depositada. Como efeito natural do programa sinérgico do MEM, valores de corrente e tensão aumentaram indiretamente em virtude da regulagem de Va para compensar a taxa de fusão. Os detalhes na medição das macrografias foram realizados como mostrado na Figura 7 e são apresentados na Tabela 2.

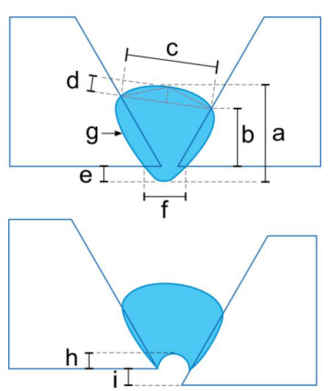
a) Espessura do Cordão;
b) Espessura Efetiva;
c) Largura da Face;
d) Convexidade da Face;
e) Altura do Reforço da Raiz;
f) Largura do Reforço da Raiz;
g) Área de Metal Fundido;
h) Concavidade Interna;
i) Desalinhamento.

Figura 7. Medições da raiz em chanfro.

Tabela 2. Valores chanfro V.

\begin{tabular}{|c|c|c|c|c|c|c|c|c|c|c|}
\hline 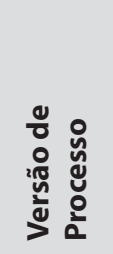 & 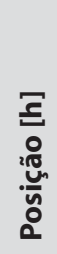 & 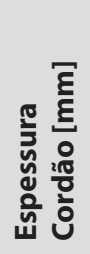 & 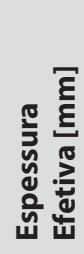 & 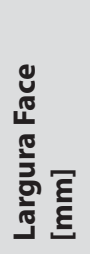 & 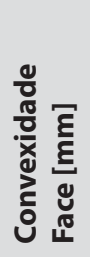 & 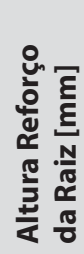 & 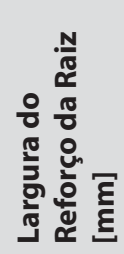 & 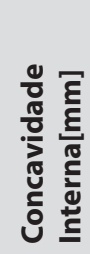 & 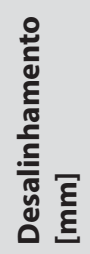 & 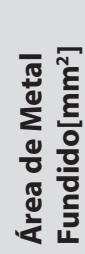 \\
\hline \multirow[t]{3}{*}{ MME1 } & 11 & 6,4 & 5,4 & 7,5 & 0,0 & 0,8 & 4,1 & 0,0 & 0,0 & 34,8 \\
\hline & 9 & 5,2 & 5,1 & 8,1 & 0,0 & 0,0 & 4,8 & 0,2 & 0,3 & 33,2 \\
\hline & 7 & 5,6 & 4,9 & 7,7 & 0,3 & 0,0 & 4,1 & 0,3 & 0,0 & 32,2 \\
\hline \multirow[t]{3}{*}{ MME2 } & 11 & 6,0 & 4,7 & 7,4 & 0,0 & 0,6 & 4,0 & 0,0 & 0,0 & 28,6 \\
\hline & 9 & 5,7 & 4,1 & 7,4 & 0,6 & 0,0 & 4,0 & 0,0 & 0,5 & 27,9 \\
\hline & 7 & 6,3 & 4,7 & 7,8 & 1,0 & 0,0 & 4,6 & 0,3 & 0,5 & 35,5 \\
\hline \multirow[t]{3}{*}{ MMEM } & 11 & 7,5 & 6,4 & 9,0 & 0,0 & 0,8 & 3,5 & 0,0 & 0,0 & 42,1 \\
\hline & 9 & 6,4 & 5,7 & 9,1 & 0,0 & 0,0 & 4,0 & 0,0 & 0,0 & 39,5 \\
\hline & 7 & 8,1 & 6,4 & 8,4 & 1,5 & 0,0 & 3,2 & 0,2 & 0,0 & 43,8 \\
\hline
\end{tabular}

Nota: ME1 - Versão MIG/MAG eletrônica nacional; ME2 - Versão MIG/MAG eletrônica estrangeira; MEM - Versão MIG/MAG eletromecânica. 
Por fim, a compilação de dados das variáveis elétricas e o valor real medido da velocidade de arame são expostos no gráfico da Figura 8. Essas medidas representam a média dos valores instantâneos aquisitados.

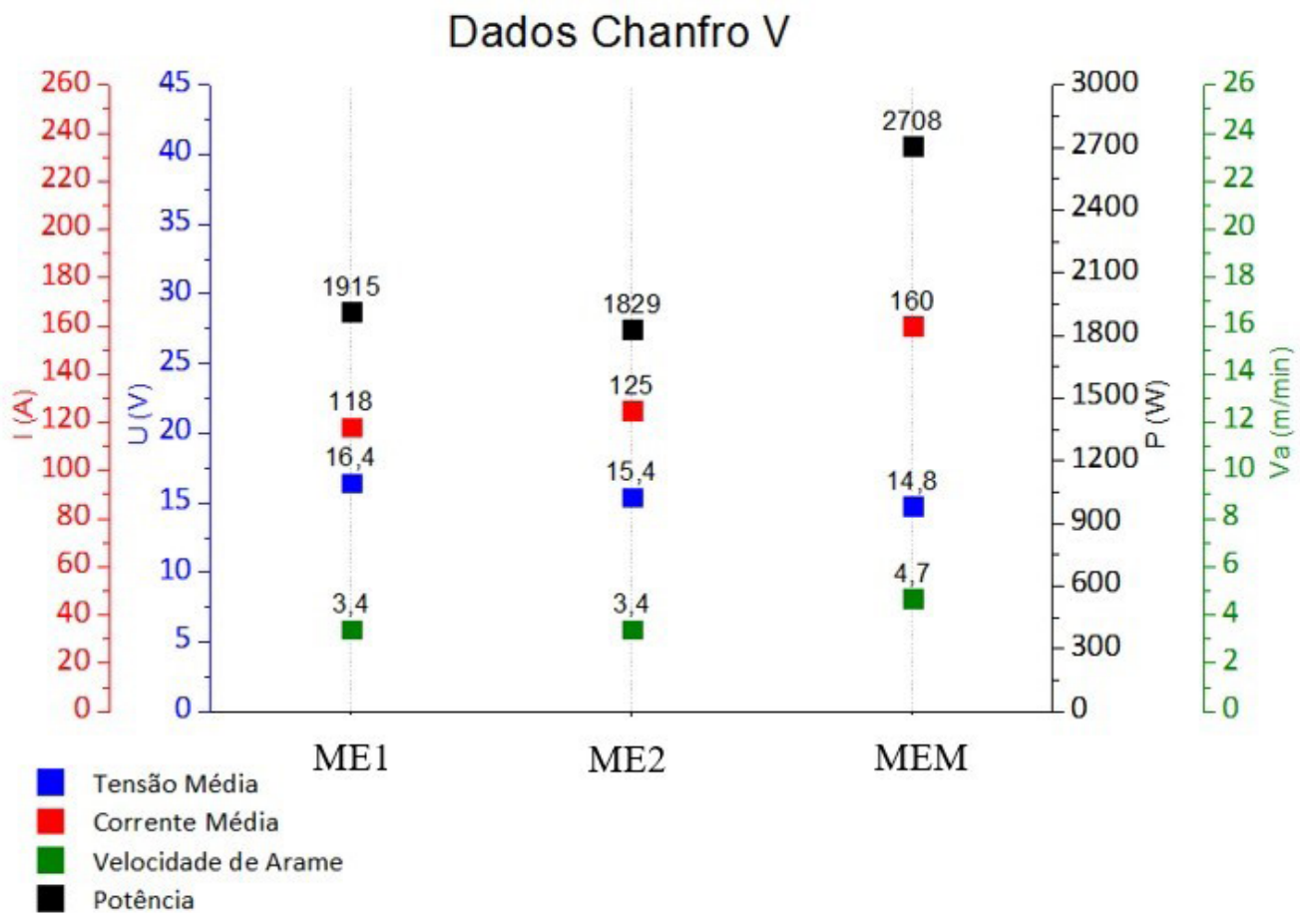

Figura 8. Dados SAP das versões MIG/MAG.

Os valores das variáveis elétricas e da Va das versões Me1 e ME2 são semelhantes, o que torna a comparação mais coerente, principalmente ao que foi exposto nas macrografias da Figura 6 com relação ao perfil geométrico de metal fundido. A versão MEM, no entanto, registrou em ferramenta de aquisição de dados uma velocidade de arame maior: em torno de 4,7 m/min. Como citado, isso explica a maior área de metal fundido depositada, mostrada na Tabela 2, a qual obteve uma variação em torno de $20 \%$ a $35 \%$ a mais em relação às outras versões, dependendo da posição de soldagem no tubo. Ademais, uma maior potência e maior corrente média foram registradas, o que é coerente para uma maior taxa de fusão do arame.

Mesmo assim, o procedimento com a versão MEM acabou ficando suscetível à falta de fusão nos flancos do chanfro. Uma hipótese levantada diz respeito ao mecanismo de transferência das gotas dessa versão. Observou-se, na comparação dos oscilogramas da Figura 4, que o tempo em curto-circuito do MEM é significativamente maior que o tempo em curto-circuito das outras versões, variando de cerca de 3 ms do ME1 e ME2 para cerca de 7 ms do MEM. $\mathrm{Na}$ avaliação do tempo relativo em curto-circuito, versus o período total, o MEM fica em torno de $45 \%$ em curto. Já nas versões eletrônicas esse valor é em torno de $15 \%$. A comparação entre as versões ME1 e MEM pode ser observada na Figura 9. Com isso, quando estiver em curto-circuito, há a extinção do arco - o que não contribuirá de forma significativa para a condução de calor no metal de base. Nesse período em curto, o principal efeito que ocorre é o aquecimento do arame por efeito Joule. Essa ocorrência em uma elevada frequência $(70 \mathrm{~Hz}$ para o MEM) tende a deixar a poça menos quente. Associado a isso, o fato de o banho metálico ser puxado no sentido contrário à ação da penetração a cada evento de destacamento da gota, em função do sistema de retração do arame, pode contribuir para a falta de fusão nesse tipo de chanfro.

Comparando a relação potência versus Va, foram feitos os cálculos com os dados da Figura 8 para cada versão: ME1 - $562 \mathrm{~W} /(\mathrm{m} / \mathrm{min}) ;$ ME2 - $537 \mathrm{~W} /(\mathrm{m} / \mathrm{min}) ; \mathrm{MEM}-576 \mathrm{~W} /(\mathrm{m} / \mathrm{min})$. Analisando os resultados, verificou-se que o MEM, mesmo com valores de potência relativa versus Va um pouco maiores, comparados aos das outras versões, tendeu a gerar falta de fusão nos flancos do chanfro "V". 
Uma Análise Comparativa entre Diferentes Versões de Variantes Modernas do Processo MIG/MAG para o Passe de Raiz em Soldagem Orbital

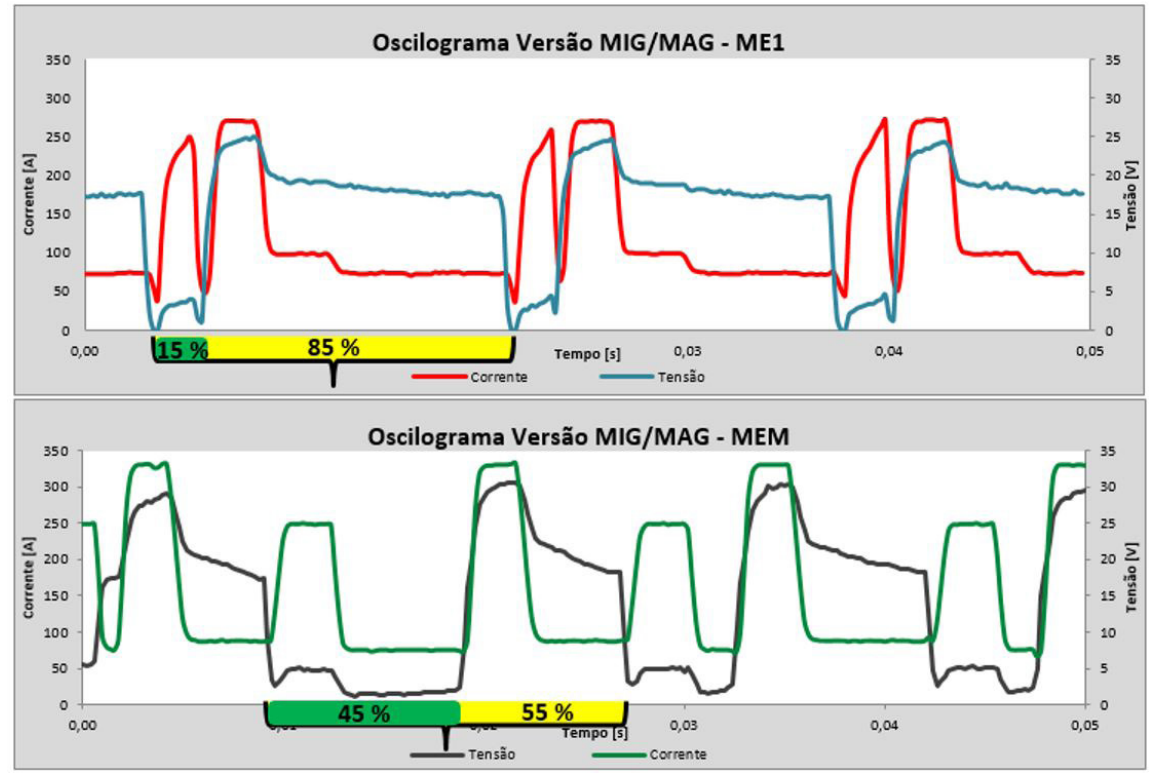

Figura 9. Porcentagem da análise do tempo em curto em relação ao período total.

Uma hipótese adicional para o comportamento comparativo apresentado está relacionada com o perfil da geometria do chanfro. O chanfro "V", comparado com o chanfro "U", possui uma quantidade maior de material (quantidade de massa), o que faz dissipar mais rapidamente o calor e dificultar a sua fusão, o que dificultaria mais a ação do MEM.

\section{Conclusões}

Nos ensaios realizados foi comprovada a possibilidade da soldagem de raiz sem a utilização de anteparo da poça (backing) em chanfro V com as diferentes versões MIG/MAG em curto-circuito com controle de corrente. Verificou-se, no entanto que, a montagem da junta é crucial, e que deve haver um rigoroso controle geométrico e controle das tolerâncias devido à ovalização dos tubos, o que pode gerar desnivelamentos (high-low) na montagem e/ou variações de espaçamento da raiz (gap).

As três versões, (duas eletrônicas e uma eletromecânica), apresentaram boa estabilidade de processo ao longo da junta, com baixa geração de respingos, resultando em cordões de boa aparência superficial e penetração total da raiz, verificadas através da análise de oscilogramas e por inspeções visuais.

Com relação ao perfil geométrico de fusão no chanfro, as versões eletrônicas obtiveram resultados expressivos em todas as posições para as condições de ensaios realizadas, sem quaisquer descontinuidades que puderam comprometer o procedimento.

Em contrapartida, a soldagem com a versão eletromecânica apresentou limitações dentro da parametrização adotada. Para os ensaios realizados nesse tipo de chanfro, sob as condições do trabalho, a versão mostrou ser vulnerável a defeitos como falta de fusão. Conclui-se que o diferenciado mecanismo de transferência da gota, embora permita obter singular regularidade de processo, exerce influência decisiva sobre a fusão e impõe diferentes faixas operacionais para boa performance, em relação às outras versões abordadas.

\section{Referências}

[1] Emmerson JG. Fcaw orbital pipe welding technology improves fab shop productivity. Welding Journal. 1999;78(11):57-59.

[2] Beeson R. Pipeline welding goes mechanized. Welding Journal. 1999;78(11):47-50.

[3] Aichele G, Bär M. Orbital welding: solutions for demanding welding tasks. Part 2. Welding and Cutting. 2005;05:252-255.
[4] Penniston C. Pipelining with precision: mechanized welding that consistently meets the challenging needs of the canadian pipeline industry. Canadian Welding Association Journal. 2013;(june):12-29.

[5] Dutra JC, Silva RGE. MIG-MAG: transferência metálica por curtocircuito sob controle da forma de onda da corrente: sistemas CCC e STT: fundamentos. Soldagem \& Inspeção. 2008;13(2):92-96. 
[6] Kim C. Back bead characteristics during butt welding of a thick plate for various backing conditions. Materials Science Forum. 2010;654-656:350-353. http://dx.doi.org/10.4028/www. scientific.net/MSF.654-656.350.

[7] Court SA, Pollard G. Inclusion chemistry and morphology in shielded Metal Arc (SMA) steel weld deposits. Metallography. 1989;22(3):219-243. http://dx.doi.org/10.1016/00260800(89)90004-9.

[8] Blackman AS, Dorling DV. Capabilities and limitations of mechanised GMAW systems for transmission pipelines. in: Proceedings of the 1st International Conference on Weld Metal Hydrogen Cracking in Pipeline Girth Weld; 1999; Wollongong, Australia. Australia: WTIA; 1999. p. 19.
[9] Amin M. Synergic pulse MIG welding. Metal Construction. 1981;13(6):349-353.

[10] Silva RHG, Dutra JC, Gohr R Jr, Cunha TVS. Soldagem e sua automação na industria de petróleo e gás: recentes desenvolvimentos do LABSOLDA/UFSC. In: Anais do 4o PDPETRO; 2007; Campinas, SP. Natal: ABPG; 2007.

[11] Sistemas e Processos para Soldagem - SPS [página da internet]. Florianópolis: SPS; 2014 [acesso em 16 out. 2014]. Disponível em: www.sps-soldagem.com.br/tartilope_v4.php

[12] Pépe NVDC. Advances in gas metal arc welding and application to corrosion resistant alloy pipes [tese de doutorado]. Cranfield: Cranfield University; 2010. 